\title{
O SISTEMA DE GARANTIA DA POSIÇAO DE LEITURA: O CONTROLE DO VEROSSIMIL EM SENHORA, UM PERFIL DE MULHER.
}

Cassiana Lacerda Carollo *

\section{PARTE}

"Uma literatura nasce sempre frente a uma realidade historica e. freqüentemente, contra essa realidade". Octavio Paz

(...) "nas camadas profundas da criação (as que envolvem a escolha de instrumentos expressivos) sempre reconhecemos como nanatural a nossa inevitável dependência". Antonio Cândido

\section{Introdugăo}

\section{Pressupostos teóricos: o uso do texto ditado pelo proprio texto}

Texto, tecido, entrelaçamento: a palavra remetendo ao efeito para o qual foi concebido. De "espaço cintilante" a "lugar de desejo", 1 a prática textual se propõe como "valor erótico e crítico" de um "objeto de fetiche", que deseja o leitor do mesmo modo que "eu desejo o autor, tenho necessidade de sua figura (que não é nem a sua representaçāo nem a sua projeção), tal como ele tem necessidade da minha (exceto no tagarelar) ${ }^{2}$

Estabelecidas as distinçōes entre "texto de prazer", "texto de fruiçāo", "informação semântica" e "informação estética" em termos de grau de utopia e gratuidade, a operação de uso é indissociável do texto, porém uso que não significa engendrar a decifração mecânica.

Assim concebido, o texto literário se propōe como atualização e, longe cie ser uma "entidade latente" ou mensagem redutivel à pura comunicação

- Cassiana Lacerda Carollo. Doutorands da Universidade de Såo Paulo, publica na revista Letras desde 1969. Colaboradora de Arquivos (UFP) e outras revistas especializadas. Acaba de entregar para publicaçáo uma leltura de Senhora de José de Alencar para a coleçáo Romances para Estudo (Editora Francisco Alves). Professora de Literatura Brasileira no Departamento de Linglística, Letras Clássicas e Vernáculas, exerce ainda, as funçbes de Diretora do Setor de Ciências Humanas, Letras e Artes.

1 CIXOUS, Hélène. Prénoms de personne. Paris, Seuil, 1974, p. 41.

2 BARTHES, Roland. O prazer do terto. Lisbog, Ed. 70, 1974. p. 66. 
cultural, a obra começa quando manifesta uma espécie de corte ou fenda, a tmese proveniente do princípio de funcionalidade.

Sua prática estando na relaçāo direta de seu efeito, exige que o texto seja lido "em sua lcitura" e como discurso orientado para o leitor.

Explicado de outra forma que nāo pelo seu efeito, não temos uma leitura, pois esta, como parte do sistema do texto, obriga a "penser la description du texte dans le système qui le régit. lui. sa parole et sa glose". 3

Fica, deste modo, afastada qualquer possibilidade da teoria substituindo c texto ou ocultando sua operaçāo específica.

Por sua vez, a teoria enquanto conhecimento das transformações operadas pela potencialidade do texto se inscreve como leitura das leituras, donde o interesse, apontado por Gumbrechet, 4 pelo conjunto de interpretaçōes de um texto como dado representativo das posiçōes de determinado contexto e como súmula do horizonte de seu entendimento em determinada ćpoca.

Porém, tal multiplicidade do texto nāo significa que ele nāo engendre uma lisibilidade ou que seu efeito não possa ser descrito por uma "leitura correta":

La réalisation correcte du texte

au point actuel de son histoire dépend

a) du texte: elle rentre dans les limites de sa correction, b) de la pratique où le texte s'inscrit:

elle se choisit dans les limites

de sa convenance avec le contexte ${ }^{5}$

Uma redução, simplista, da teoria do texto incide na descrição de sua eficácia (retórica do efeito) enquanto "forma", pressupondo uma prática que faz da história uma dimensão imanente (do texto), razão pela qual "esquecer" a história "é omitir sua função". 6

Este uso do texto/previsto pelo e no texto, permite, por sua vez, a distinção entre as leituras: a teórica ou do teórico que procura estabelecer s efeito objetivo, a crítica que interpreta o efeito de leitura e a do usuário aue sofre o efeito do livro.

Interessados na interpretaçāo do efeito de leitura, somos também obrigados a pensar o texto de Senhora como romance, vale dizer como um modo de texto institucionalizado funcionando (ou que funciona) como código de uma sociedade que se recita, ou como modo é resultante do controle garantido pelo uso institucionalizado da literatura.

Esta "redução explícita do texto" a uma unidade pode ser perseguida rela intervenção (explícita) de uma censura (regime, fatos, aprovação ou re-

3 GRIVEL, Charies. Production de l'intérêt romanesque. Paris, Mouton, 1973. p. 28 .

4 GUMBRECHET, Hans H. Apresentação. In: —et alii. La actual clencia literária alemana. Salamanca, Amaya, 1971.

5 GRIVEL, p. 33.

6 Ibid., p. 21. 
provação da época) e. implicitamente, pelo sistema de publicaçāo e escrita estabilizada.

Evidentemente uma proposição mais ampla ou uma leitura teórica imporia o exame das formas de procedimento de um determinado efeito textual, considerando a convergência de textos, sincrônicos, na medida $\mathrm{em}$ que o que modifica e atualiza só é avaliável pelo estudo das possíveis transformações na série e dentro do sistema da literatura, além das implicaçōes de seus niveis decorrentes da demanda social (literatura oficial, sub-literatura, literatura popular, etc.).

Consequientemente, a descrição do efeito enquanto organização no texto e a descrição "fora do tcxto", isto é, em relação aos seus análogos, são exercícios que devem caminhar juntos.

A leitura do efeito romanesco enquanto produção/reprodução, como prática que engendra o ideológico, noção que Adorno, em sua "Conferência scbre lírica e sociedade", já apontava para o seu alastramento incômodo. torna conveniente refletir sobre o caráter privilegiado do lugar do texto:

a grandeza das obras de arte, contudo, consiste unicamente no permitirem expressar o que a ideologia encobre. Seu êxito próprio. quer elas queiram quer não, vai além da falsa consciência. 7

Por sua vez, Alain Badiou, analisando o romance como prática ideológica, reafirma seu caráter de modo de produção estética, de estrutura que submete o material, de modo que estes possam funcionar como ideologias.

Em termos kristevanianos, o romance é "um texto fechado", pois um "texte lit l'histoire et s'insère en elle", 8 ainda que no momento de seu "não fechamento" ele negue, modifique, transforme o real:

le récit en dit toujours moins qu'il

n'en sait, mais il fait souvent savoir plus qu'il n'en dit. 9

\section{A verdade da fiç̧ão: nívels de Intenção de significar}

Conforme insistimos, a ficção enquanto modo de ser corresponde à inversão da relação causa efeito, o que não exclui a constituiçăo de um assunto como origem do sentido.

Esta situação de base, alargada por registros que criam a condição de leitura: efeito de temporalização, espacialização, modos narrativos, etc., são eiementos ligados à credibilidade vale dizer, ao verossímil do texto e à leitura definida enquanto ato mimético. "Fora de moda" ou "condenado", o verossímil é também um elemento implícito da topologia do discurso, pois

7 ADORNO, T. Conferéncia sobre lírica e sociedade. In: OS PENSADORES. Sāo Paulo, Abril, 1975. v. 15, p. 203.

8 KRISTEVA, J. Seméiotike; recherches pour une sémanalyse. Paris, Seuil, 1969. p. 443 e 79 .

9 GENETTE, G. Figures III. Paris, Seuil, 1972. p. 213. 
o narrar é fixaçāo de um lugar onde o livro é lisível, o que impōe uma situação de leitura que prevê o funcionamento do ato intelectivo.

O discurso, como um lugar que vai para outro, faz do sujeito "um posto de observação", havendo na própria notação ato mimético/ato diegético uma relação entre quantidade de informação/presença do informador, caracterizando-se a mimesis, segundo Genette, por um máximo de informação e minimo de informador.

A presença do narrador como fonte de organização, oralização e unificaçāo da narrativa, pode ser problematizada em termos de narrador e leitor implícitos ou explícitos, enunciado-enunciaçāo, porém, é antes de tudo uma prática de acumulação de sentido, cuja dependência está estritamente ligada

From point to point we follow the writer always looking back to the subject itself in order to understand the logic of the course he pursues 10

La lecture ne peut être prévue dans le texte que si celui-ci se donne vraissemblable, que s'il réussit à fournir les moyens propres a sa reconnaissance. 11

Porém, não é o verossímil no sentido vulgar naĩ, como natural ou aprecnsăo do mundo que nos interessa. mas o verossímil que pressupõe relação com o efeito inter-discursivo.

$E$, é na noção de verossímil já presente em Aristóteles, isto é, como sєnso comum, discurso anônimo que centraremos um primeiro ponto de interesse. Refletindo a resposta do discurso literário ao discurso natural ou, segundo Kristeva, a historicidade do verossímil como dado do código e daí ideológico, torna-se necessária a discussão das implicações realismo, cultura, linguagem.

A segunda noção de interesse é a de conformidade de gênero e de conformidade de tipo verificadas na configuraçāo de propriedades estruturais e na relação com determinado corpus:

Le vraissemblable, pris dans ce sens, désigne la rélation de l'oeuvre avec le discours littéraire plus exactement, avec certains éléments de celui-ci, qui forment un genne.12

Tal prática de verificabilidade da informaçāo e o reconhecimento do leitor, tornado possível pelo sistema de garantia de perspectiva criada pelo narrador, bem como a proposta de relacionamento inter-discursivo, virāo apoiar rosśa proposta de leitura de Senhora. de José de Alencar.

10 LUBBOCK, P. The craft of fiction. London, J. Cape, 1966. p. 23.

11 GRTVEL, p. 97.

12 TODOROv, T. Poétique In: QU'EST-SE que le structuralisme? Paris, Seuil, 1968. p. 144. 
Evidentemente, nāo esquecemos que o verossímil romanesco funciona como estratégia de ocultamento da ficção. pois "la vraissemblance est la marque dont s'affublent les lois du texte". 13

Esta posiçāo autoritária do narrador e a forma pela qual sustenta a unidade do discurso cria uma "cegueira" quanto ao funcionamento do livro. fixando o leitor na história. Acabando por reafirmar a verdade que o leitor possui o narrador impōe uma "interpretação naturalizada".

E como cumplicidade ou efeito de cumplicidade que o verossímil nos preocupa. Ainda que saibamos que as proposiçōes verossimilhança, demonstração, romance, confirmaçāo, ao nivel da articulação narrativa, elas sofrem o efcito da relativizaçāo como desnivel da garantia, pois neste momento o rarrador surge para o sistema relacional como um produto de sua realizaçāo.

Este desnivel, por sua vez, é duplamente interessante, traduz a diferença entre o efeito visado e o efeito produzido e revela a necessidade de distinguir as várias intenções de significar: explicitada, implícita, revelada na estrutura com intençāo "real" ou "sentido do sentido".

\section{Proposlção}

"Perfil de mulher", instltuliçăo literária e escolha de instrumentos expressivos.

A obra de Alencar, examinada a partir da ótica da literatura enquanto instituição, promovendo intervençōes explícitas e implícitas da sociedade que se recita, deve, no caso brasileiro, ser pensada também de maneira que seja levada em consideração a dialética da fidelidade ao local e mobilidade mundial.

O esforço consciente em torno da assimilaçāo de modelos propondo a distinção entre a imitaçāo e assimilação, já apontando para o problema da influência como um fato de nossa cultura, além de ser um sintoma de maturidade na afirmação do nacional, situa Alencar como um autor privilegiado. pois "... ninguém melhor que Alencar representou em nossa literatura o fenômeno da nacionalidade resultando na universalidade". 14

No momento em que se discute a noção de "texto Geral", discutir questōes nacionalistas passa a ser não só "aberração moral, é também uma falácia estética. No entanto, se não há escolas nem estilos nacionais em compensação, há famflias, estirpes, tradiçōes espirituais ou estéticas". 15

Por outro lado, o problema da influência ou resistência às pressōes culturais externas é parte integrante de nosso pensamento e fator que se efetivou em manifestações cujo interesse passa a ser também específico da criação literária.

13 TODOROV, T. Introduction au vraissemblable. In:-—. Poétique de la prose. Paris. Seuil, 1971. p. 94.

14 AMOROSO LIMA, Alceu. José de Alencar esse desconhecido? In: ALENCAR, Jose de. Iracema. Ed. do Centenário. Brasilia, INL, 1965. p. 46. 
Ninguém mais do que Alencar se debateu em torno dos problemas da aceitação e/ou reprovação pública, dificuldades do nosso sistema de publicação, influência e/ou imitação.

Enquanto a pressão social e condiçōes de mercado impunham o debate cm torno da escolha de temas refletindo posiçōes ora de extremo nativismo ora de servilismo, Alencar parece refletir em sua criação e em seu pensamento crítico a visão do problema sob uma forma mais profunda. Se não resolveu a questão em termos de "uma justificação crítica da assimilação" 16 ou de uma vinculação de um resultado histórico a uma origem artística que sobrepusesse a forma à forma, mesmo permanecendo no terreno da contradiçāo Alencar traduz uma situação. Neste sentido sua polémica com Nabuco é uma manifestação no campo teórico da consciência do autor para com o desconcerto ideológico brasileiro manifestado no contra-senso de um sistema de idéias importadas e incorporadas por razões inaceitáveis, o que é verificável no seu impasse quanto a transplante de um modelo artístico. "Nabuco é perspicaz em suas criticas, põe o dedo em fraquezas reais, mas para escondê-las; Alencar, pelo contrário, incide nelas tenazmente. guiado pelo senso de realidade, que o leva a sentir, precisamente aí, o assunto novo e o elemento brasileiro. Ao circunscrevê-las sem as resolver, não faz grande literatura, mas fixa e varia elementos dela". 17 A leitura de Senhora proposta por Roberto Schwartz aponta para as dificuldades e contraciiçōes do autor na tranşposição formal do desajuste local e incorporaçāo do sistema capitalista, o que, segundo ele, resulta na duplicidade de diç̧ōes, uma de alto alcance universal $\mathrm{c}$ ideológico $\mathrm{c}$ outra que incorpora legitima, a sobrevivência rotineira e é sustentada pelo quadro local, dando assim a um só romance dois efeitos de realidade", vale dizer, comprometendo a lógica de interesse discurso. Acabando por concluir pela "audácia das contradiçōes" e não conformismo do autor, suas contradiçōes abrem a possibilidade de uma leitura por outro prisma, sobretudo quando ressalta a união "falência formal e força mimética" e distingue conformismo de conciliação.

Evidentemente, esta associação da polêmica formal à forma mimética é um tanto paradoxal, sobretudo pelo fato daquele crítico em nenhuma hipótese estar empregando o termo mimesis no sentido naif. Além disso, a proposição pode ser problematizada, quando questionada em termos de intenção explícita c intençāo implícita, verificadas através da estrutura revelando o efeito visado.

A propósito do segundo caso, a constataçāo de Antônio Cândido sobre a transposição, no plano da estrutura do livro, do mecanismo da mercantilização é sempre oportuna:

15 PAZ, Octavio. Signos em rotação. Sāo Paulo, Perspectiva, 1972. p. 126.

16 ANTONIO CANDIDO. Literatura e subdesenvolvimento. Argumento, Rio de Janeiro (1): 19, out. 1973 .

17 SCHWARZ. Roberto. Criandc o romance brasileiro. Cadernos de opiniño, Rio de Janeiro (1): / 41, 1975. 
Se (...) atentarmos para a composição de Senhora, veremos que repousa numa espécie de longa e complicada transação (-) Vemos que o comportamento do protagonista exprime, em cada episódio, uma obsessāo com o ato de compra a que se submete por causa de motivos econômicos (-). E as próprias imagens do estilo manifestam a mineralização da personalidade, tocada pela desumanização, capitalista, até que a dialética romântica do autor recupere a sua normalidade convencional. No conjunto, como no pormenor de cada parte, os mesmos princípios estruturais informam a matéria. 18

As duas leituras, como vimos, permitem a possibilidade de verificaçāo dos seguintes aspectos: a complexidade deliberada do livro, sua força mimética, a coerência do conjunto refletida em cada pormenor, e incidem num mesmo aspecto: o caráter conciliatório do final, de certa forma incompatível com a ordenação geral da obra.

De nossa parte, entendendo este final como recuperação da paz arquetipica, obtida como recompensa da luta pela felicidade íntima, o que nos leva a acreditar na ausência de adequação conformista de natureza social. Também a característica moralizadora e edificante da obra permite situar neste arquétipo abstrato o edifício idcológico da obra. E o que parece já estar presente em Balzac, em Splendeurs et Misères des Courtisanes, quando diz: "Le bonheur n'a pas histoire et les conteurs de tous les temps l'ont si bien compris cette phrase: ILS FURENT HEUREUX! termine toutes les histoires d'amour".

Mesmo aceito o caráter moralizador da obra, o sistema de garantia da ótica de leitura, sustentada pelo narrador com sua visão racional, integradora. passional e participante, é um dado que se propõe como mantenedora coerência do conjunto em relação ao final e força mimética.

Vale dizer, o estudo da proposta do efeito de leitura de Senhora se impondo como interpretaçāo naturalizada, na medida em que é registrada por elementos posicionais ligados à noção de credibilidade e verossimilhança, parece confirmar a proposta de que, afirmada uma verdade, tudo converge para a veracidade do texto:

Ce que le roman affirme au niveau explicite du texte (A savoir sa vérité) se trouve 1) vérifié (fictivement) au niveau de l'intention implicite (structurale) 2) $n^{\prime}$ existe qu'afin de couvrir son opération réelle. Loin d' accomplir ce qu'il parait s'assigner à lui-même comme tâche (l'imitation), le roman constitue la vérité a laquelle il est censé se conformer et vérifier sa propre fiction $(\ldots)$ Le récit rend "vrai" sa prétention (affichée) au vrai; il est technique d'obtention - et d'ostentation du vrai, véracité fabriquée. autrement dit: vraissemblance. 19

Some-se ainda a relação plano do narrador - adesāo do leitor como princípio que rege os efeitos ligados à comunicação textual, predetermina-

18 ANTONIO CANDIDO. Critica e sociologia. In:-. Literatura e sociedade. 2. ed. São Paulo, Ed. Nacional, 1967. p. 6.

19 GRIVEL, p. 244-5. 
dos a serem aceitáveis, trazendo as conseqüências de uma estrutura determinada à eficácia ideológica, o que dificulta a conciliação falência formal forma mimética, coerència estrutural consciência ideológica. E neste ponto que alguns autores preferem situar o próprio prazer do texto: na emoção resultante deste processo especular, que estabelece o sentido arquetípico na medida em que verifica a efetivaçāo de um código possuído.

Por sua vez, a situaçāo de Senhora como livro da série "perfis de mulher", além de ampliar o sistema apontado através do questionamento das proposições apreendidas através de leituras contemporâneas, permite sua avaliação, pela percepção da verdade como efeito de gênero, levantado a supor correspondências contextuais e intercontextuais.

Dito de outra forma, ao apoiar a defesa da veracidade do livro no critério das categorias constitutivas do que chamou "perfil de mulher", Alencar passa a discutir o efeito de verdade através da dependência a determinados limites e modelos, cujo interesse faz com que busque apoio desmentido, vale dizer, na verossimilhança do verossimil:

Esses perfis de mulher, como diz o termo, nāo sāo tipos; mas, ao contrário, exceçōes ou idiossincrasias morais, que se tornam curiosas, justamente pela originalidade e aberração do viver comum. E assim que se deve entender Lúcia, Emilia e Aurélia. 20

\section{Imitar uma imitaçāo: o "tamanho fluminense romance fislológico"}

A homologia entre retórica e ideologia, como forma de evidenciar a relaçāo entre o uso institucionalizado da literatura, várias intençōes de significar etc., torna indispensável uma breve referência sobre a evolução intelectual de Alencar, sobretudo pelo fato de que a compreensāo de suas obras como projeto vem precedida de um "ante-projeto" global, polêmicas que funcionam como sintomas de sua posição quanto à censura, aprovaçāo e reprovaçāo do público. Os debates do autor, no entanto, ganham proporçōes de causa e efeito, tornando-se dificil dissociá-los das obras, que refletindo a intençāo programática e de auto-defesa, acabam por instaurar um processo metalinguístico, pois "sempre que o remetente e/ou destinatário tem recessidade de verificar se estāo usando o mesmo código o discurso focaliza c Código". 21

Em "Como e porque sou romancista" (1866) Alencar resume suas convicçōes, gostos, transformações e lutas e. da mesma forma que nos prefácios e artigos de crítica, queixa-se da "rota aspérrima" que teve que "abrir através da indiferença e do desdém".22 da "crítica de barrete" ou de "esquina" do "caiporismo de nossa arte tipográfica".

Apesar de situar o periodo de 1866-70 como o da "velhice literária" (razão pelat qual adota o pseudónimo de Sênio) ao escrever Senhora nesta mesma

20 ALENCAR, José de. As quintas. In. COUTINHO, Afranio, org. A polémica Alencar-Nabuco. Rio de Janeiro, Tempo Brasileiro, 1965. p. 150.

21 JAKOBSON, R. Lingüística e comunicaçūo. Sāo Paulo, Cultrix, 1969. p. 127.

22 ALENCAR, José de. Fiç̧ão completa. Rio de Janeiro, Aguilar, 1965. p. 118. 
época retomará o pseudónimo de que se valeu ao escrever - Luctola e, fosteriormente, em Diva.

De modo que o "tom" de descrença em relaçāo às potencialidades de nosso meio literário e político acompanha a grande maioria de pronunciamentos do autor que, finalmente, no prefácio aos Sonhos de Ouro (1872) retoma a questão das dificuldades de publicação, acusando a "musa industrial do Brasil" como responsável "pelo caráter pouco profissional de nossas letras".

E sintomática, também, neste mesmo prefácio, a posição assumida para com a critica, seja ela moralista ou tenha ela o dogma da contrariedade ao concluir: "E para a crítica sisuda que te quero eu preparar". 23

Porém, o aspecto de maior relevo, e que acaba assumindo o caráter de sustentáculo da obra. é a discussão em torno da literatura nacional, onde inscreve o projeto global de sua obra.

E preciso desde logo chamar atenção para a posição lúcida da discussāo. que afasta de imediato ilusões sobre a nacionalidade de nossas letras ou "futilidade de patriotismo", isto ao que definir literatura nacional como "alma pátria que transmigrou para este solo virgem com uma raça ilustre, aqui impregnou-se da seiva americana desta terra (...) e cada dia se enriquece ao contacto com outros povos e ao influxo da civilizaçāo". 24

Situa, entāo, os perfis de mulher como obras que traduzem a fase em que a sociedade brasileira tem "fisionomia indecisa", decorrente da importação contínua de idéias e costumes estranhos, que "devem por força de comover uma sociedade nascente, naturalmente inclinada a receber o influxo da civilizaçāo". 25 "Como criança, esta sociedade imita, cabendo aos escritoles buscar modelos próprios que lhe "dêem os últimos traços e formem o verdadeiro gosto nacional". 26

Sonhos DYuro tem ainda no sub-título um índice importante, ligado a proposta: "romance brasileiro". Porém o autor reconhece que, como "flor que se aclimata". os livros desta fase poderão sofrer restriçōes de "configuração estrangeira ou de arremedo", mas justifica que adotar tal posição $\epsilon$ "nāo conhecer a sociedade brasileira que está a faceirar-se pelos salőes e ruas com atavios parisienses". 27

A importáncia instaurada pelo traço de metalinguagem contido no sub-título e sua relaçāo com dados contextuais e inter-discursivos mereceria um estudo especial, o que foge da extensão de nosso trabalho. Ainda que possa ser discutida a classificação do "romance fisiológico" ou "estudo da alma", os "perfis de mulher" se propōe como modelo nacional, razão pela qual nestas obras o modelo estrangeiro é refutado.

Porém, são raras as críticas aos "perfis de mulher" que não incidam

23 ALENCAR, Ficçăo..., p. 494.

24 Ibld., p. 495.

25 Ibid., p. 496.

26 Ibid., p. 495.

27 Tbid., p. 495. 
no fator imitaçāo: Luciola é aproximada de La Dame aux Camélias, de Dumas Fils; Dlva, do Roman d'un jeune homme pauvre, de Feuillet; e Senhora, de M. de Carmors, do mesmo autor. 28

Deste modo, é interessante o exame das situaçōes em que o "provável nodelo" é evocado e o discurso assume a posiçāo metalingüística.

Em Luciola, no capítulo XV, a protagonista é surpreendida lendo o livro riuito conhecido A Dama das Caméllas, o que leva o narrador-personagem a interrogar se a leitura resultara da "simpatia moral" ou se "Lucia refutando a obra de Dumas "como uma mentira" permite com Paulo amplie o assun10". "Uma poética exageração, mas uma mentira, nāo!"

A discussão é encerrada reafirmando a distância entre as duas obras: "Está bem. deixemos em paz A Dama das Camélias. Nem tu és Margarida. ncm eu sou Armando". 29

Apesar das discussōes em torno das influências estrangeiras haverem merecido a longa exposição do pósfácio de Diva, Nabuco acusará Alencar de plagiar Dumas, sendo contestado por Alencar que sustenta sua argumentação no conceito de "perfil de mulher" e lembra que a obra "bem longe de ser imitaçāo da Dame aux Camélias é, ao contrário, sua cabal refutação".

O próprio texto do livro acusa este intuito e, explica mais adiante, "Alexandre Dumas quis provar no seu livro que a mulher pode regenerar-se pelo coração, rara vez se poderá regenerar para o amor feliz". 30

Diva, conforme séu posfácio, sofreu censuras do modismo parisiense, sobretudo quanto à não obediência às normas cultas, neologismos e estrangeirismos. Porém, o que parece ser dado de maior significação é a influência da reprovação pública para com Lucíola, obra que se nāo chegou à intervenção da censura, como no caso da peça Asas de um anjo, mereceu a reprovaçāo do imperador pelo seu caráter licencioso. Ora. Diva é a "heroína que vem pudicamente vestida", a antitese de Lucíola Nesta ordem de idéias, como situar Senhora?

28 Neste tópico das "imitaçōes", apesar da inexistência de trabalhos sustentados na metodologia comparatista, a critica continua a repetir a lista de influências possiveis. Raimundo de Magalhães Jr., no capítulo (Quando Alencar imitara” (José de Alencar e sua época 2. ed. São Paula Lisa, 1971) ainda sugere aproximaçōes de Diva com a Patinho Feio de Andersen, de Senhora com le maitre des forges de Georges Onhet. No entanto. é de maior importância notadamente pela perspectiva adotada, o estudo de Décio de Almeida Prado "Os Demonios familiares de Alencar" (Revista do Instituto de Estudos Brasileiros, São Paujo (15):27-57, 1974), onde as aproximaçōes com modelos estrangeiros sāo resultado de verificação detalhada. Aém deste aspecto no referido estudo è ressaltada a importáncia do conhecimento do teatro de Alencar pela sua intima relaçăo com a obra do romancista. Estudando o tema do casamento e/ou dinheiro na obra teatral de Alencar. caracterizando as posiçōes do autor quanto ao tema do amor a partir do modelo adotado em O Crédito. Esta peça, que José Verissimo já aproximara de Question d'Argent de Dumas, também desenvolve o motivo do casamento por interesse, porém, o ensaista ao verificar o conjunto de textos abordados conclui pels complementaridado das teses sobre a defesa domo delo nacional e presença do modelo estrangeiro.

29 ALENCAR, Ficçāo..., p. 293-3.

30 ALENCAR, As quintas, p. 150. 
A conversaçāo aparentemente despretensiosa sobre Diva, no capítulo II, na quarta parte de Senhora, ganha o caráter de integraçāo semântica pelas referèncias "às críticas de condenação dogmática", permitindo que seja tematizado o espaço da história de Aurélia. Instaurando a diferença entre o antes e o fora da escrita: Mal pensava Aurélia que o autor de Dlva teria maais tarde a honra de receber indiretamente suas confidencias e escrever também o romance de sua vida p. 800 ). O dialogo continua plicita a preocupação do autor pela verossimilhança do caráter das personagens:

E um tipo fantástico, impossível! sentenciou o crítico. Acrescentou ainda algumas coisas acerca do romance, cujo estilo censurou de incorreto, cheio de galicismos, e crivado de erros de gramática.

o desenlace especialmente provocou acres censuras (...)

A noite apareceu o crítico.

- Ja li Diva disse depois de responder ao cumprimento.

- Então? Não é uma mulher impossível?

- Não conheço nenhuma assim. Mas também só podia conhecê-la Augusto, o homem que ela amava, e o unico ente a quem abriu sua alma.

- Em todo o caso é um caráter inverossímil.

- E o que há de mais inverossímil que a própria verdade? retorquiu Aurélia, repetindo uma frase célebre. Sei de uma nova...

Se alguém escrevesse sua história, diriam como o senhor: "E impossivel! Esta mulher nunca existiu". Entretanto eu a conheci. 31

Deste modo. Diva não é apenas um livro de cabeceira de Aurélia, o que não reduziria sua importância, pois, a exemplo de Rousset quando estuda os "livros de cabeceira das personagens de Proust. notamos que as escolhas apontam "a certaines encontres ou convenances du personnage avec um livre ou un auteur", 32 fato que é um indice da ordenação da Recherche que, segundo aquele ensaista, não é só um romance da criação, mas que se constrói em torno de experiências estéticas.

Na mesma ordem de idéias, outro recurso adotado é o da leitura e gostos estéticos de suas personagens: Byron é autor favorito e imitado por Seixas, enquanto Aurélia manifesta restrições ao caráter ultra-romântico "do ardo inglês", George Sand é lida com certa displicência por Aurélia, Lamartine imitado por Seixas. Já Otelo de Shakespeare, a Norma de Bellini e a épera Favorita são espaços artísticos evocados como reduplicação de conteúdo e formas, ou com sentido crítico.

No entanto. Diva é lembrada para acentuar a lógica de açōes que orienta o discurso do tipo "perfil de mulher" centrado no estudo da alma, no "caráter singular" onde o indivíduo sobrepōe-se ao tipo. Verificando o uso do código, será garantida uma ótica determinada de leitura, ampliando-se aos dois livros a defesa da credibilidade.

31 ALENCAR, Ficção .... p. 800.

32 ROUSSET, Jean. Forme et signification. 8. ed. Paris, Corti, 1973, p. 156. 
O tópico da imitação é também refutado no interior do livro:

Seixas estava muito longe de ser um Camōes, mas já nele começava o embotamento do senso moral, que é o influxo de uma civilizaçāo adiantada, e no seio de uma sociedade corroída como a de Paris, acaba por abortar aqueles monstros. Para o leão flumimense, mentir a uma senhora, insinuar-lhe uma esperança de casamento, trair um amigo, seduzir-lhe a mulher eram partes de um jogo social, permitidas pelo código da vida elegante.

A sociedade em formação, o processo de influências estrangeiras desviam Seixas do modelo de Feuillet. 33

A personagem, vista como um produto fluminense, instaura-se e definc-se como oposta ao produto da civilizaçāo e da sociedade parisiense, apesar de sofrer o influxo da influência de costumes estranhos aos locais.

o mesmo aspecto desloca uma possivel crítica apoiada na ideologia realista, preocupada em refletir o processo global da degradação capitalista, para a crítica à imitação sem bases sócio-econômicas ou culturais e, portanto, limitada ao nivel da convencionalidade social.

A categoria de tipo em que se inscreve Seixas ("herói bom mas fraco") é fundamental para a manutenção da coerència do sistema de melhoramento, sendo argumento para a nota introduzida no segundo volume da 1.: edição. Bu

Discutindo reparos feitos ao livro, a referida nota retoma a questão de v'ma possível aproximaçāo com a obra de Feuillet, apoiando-se na conceituação do "tamanho fluminense" da sociedade em que gira a história, fator ligado ao cunho nacional da obra já que o "tamanho" da sociedade é o resultado do processo de influências. Porém, a maior parte da defesa liga-se ao caráter verdadeiro da história e à fidelidade dos fatos narrados 35 para explicar as contradiçōes de Aurélia no modelo adotado ("estudo" ou "perfil moral").

A singularidade da personagem, deste modo, opō-se à noção de tipo anteriormente aplicada para explicar o comportamento de Seixas (cópia da

33 ALENCAR, Fiçäo..., p. 732. O grifo é nosso.

34 Senhora teve sua 1." edição publicada em dois volumes, o primeiro contendo as partes I e II, e o segundo as partes III e IV, notas e erratas. O Titulo vem intencionalmente grafado Senhôra (logo lê-se a palavra ao longo da obra na forma culta da época, isto $e$, com "o" fechado). A nota assinada por uma leitara de nome Elisa do Vale vem sendo atribulda a Alencar. Alguns ainda referem-se a coincidêncis do nome com o título da obra de Balzac, Les lys dans la vallée. Tamberm Ehisa era o nome de uma filha de Alencar, outro argumento evocado como fator da autoria... Conforme a explicaçáo incluida pelo autor a carta fora publicada no Jornal do Comércio "por uma amiga da escritora", que discute os reparos feitos por uma leitora assinada Paula.

$35 \mathrm{Em}$ Luciola, o "prefácio do autor" insiste na imagem verdadeira de mulher e na veracidade da história que chegou so conhecimento do autor por intermédio de uma amiga das personagens. Diva é também um romance que resultou da leitura de um manuscrito, é "um retrato natural", e finalmente Senhora, como já nos referimos, é o resultado de um drama real, conforme a própria obra tematiza. 
sociedade atual), e é sustentada no gênero de discurso em que se inscreve, ou scja: "romance fisiológico" ou "perfil de mulher". A posição de tal modelo parece afastar um possívcl tom moralizante, na medida em que é sustentado na combinação drama, narrativa. descrição, fato que permite que as personagens "se desenhem a si mesmas no correr da ação".

Este segundo aspecto é exemplificado pela "leitora-defensora", quando ressalta o sentido da descriçāo do aposento de Seixas que "desenha seu habitante $^{n}$. O aspecto dramático, por sua vez, é facilmente perceptível, verificável, através das referências às personagens como atores.

Convem, ainda, chamar atenção para o argumento proposto como defesa às possíveis acusações quanto à verossimilhança da fábula, quando casam.ento de conveniência é visto "coisa aceita e respeitada pelo mundo", sendo o amor romanesco de Aurélia, o verdadeiro "responsável pela distorsāo do fato que para ela assume as proporçōes de miserável transação".

\section{REFERENCIAS BIBLIOGRAFICAS}

ALENCAR, José de. Fiçäo completa. Rio de Janeiro. Aguilar, 1965. v. 1.

ב. Iracema. Ed. do Centenário. Rio de Janeiro, INL 1965, $220 \mathrm{p}$.

ALMEIDA PRADO, Décio de. Os demonios familiares de Alencar. Revista do Instituto de Estudos Brasileiros, São Paulo (15):27-57, 1974.

ANTONIO CANDIDO. Literatura e sociedade. 2. ed. Săo Paulo, Ed. Nacional, 1967. $220 \mathrm{p}$.

- Literatura e subdesenvolvimento. Argumento, Rio de Janeiro, (1)-7-24, out. 1973.

BARTHES, Roland. O prazer do texto. Lisbon, Ed. 70, 1974.119 p.

CIXOUS, Hélène. Prénoms de personne. Paris, Seuil, 1974. $331 \mathrm{p}$.

COUTINHO, Afrânio, org. A polêmica Alencar-Nabuco. Rio de Janeiro, Tempo Brasileiro, 1965. $219 \mathrm{p}$.

CENETTE, Gérard. Figures III. Paris, Seuil, 1972. 285 p.

GrIVEL, Charles. Production de l'intérêt romanesque. Paris, Mouton, 1973. $428 \mathrm{p}$. GUMBRECHET, Hans et alii. La actual ciencia literaria alemana. Salamanca, Amaya, 1971. $270 \mathrm{p}$.

JAKOBSON, Roman. Lingüistica e comunicação. São Paujo, Cultrix, 1969. 162 p. KRISTEVA, J. Seméiotike; recherches pour une sémanalyse. Paris, Seuil, 1969. 167 p. LUBBOCK, P. The craft of fiction. London, J. Cape, 1966. $277 \mathrm{p}$.

MAGalfaES JR., Raimundo de. José de Alencar e sua época. 2. ed. Sāo Paulo, Liss, 1971. $358 \mathrm{p}$.

PAZ, Octavio. Signos em rotação. São Paulo, Perspectiva, 1972. 320 p.

OS PENSADORES. São Paulo, Abril, 1975. v. 15.

QU'EST-CE que le structuralisme? Paris, Seuil, 1972. $441 \mathrm{p}$.

ROUSSET, Jean. Forme et signification. 8. ed. Paris, Corti, 1973. 194 p.

SCHWARZ, Roberto. Criando o romance brasileiro. Cadernos de opiniāo, Rio de Janeiro, (1):41-53, 1975.

TODOROV, T. Poétique de la prose. Paris, Seuil, 1971. $353 \mathrm{p}$.

Letras, Curitiba (25): 51-64, jul. 1976 
Carollo, C. L. Sistema de garanlia da posição de leitura

\section{Resumo}

A primeira parte deste trabalho discute o papel exercido pelo efeito engendrado pelo próprio texto e pelo horizonte de entendimento de uma obra em determinada época.

O gênero ou forma "perfil de mulher" será visto no conjunto da obra de Alencar e como parte de um projeto que reflete a obra em questāo como sistema instaurado pela previsibilidade de leitura, que funciona no próprio fazer e é fixada no clima de cumplicidade e de reconhecimento de uma informação, orientada para os limites de conveniência com o contexto.

\section{Résumé}

La première partie de ce travail propose le questionnement de l'effet produit par le texte, c'est à dire la mise en situation de lecture et les dégrés de compréhension d'une oeuvre dans un moment donné. Le genre (ou forme) "profil de femme" sera envisagé dans l' ensemble du projet de l'oeuvre de Alencar comme une proposition qui fait du discours de Senhora un système qui joue avec la prévisibilité des réactions de lecture, fontionnant dans le récit et la complicité de reconaissance d'une information orientée vers les limites de sa convenance avec le contexte. 